\title{
Overexpression of Allograft Inflammatory Factor-1 Promotes the Proliferation and Migration of Human Endothelial Cells (HUV-EC-C) Probably by Up-Regulation of Basic Fibroblast Growth Factor
}

\author{
JUN JIA, YU CAI, RONG WANG, KANG FU, AND YI-FANG ZHAO
}

\begin{abstract}
Key Laboratory of Oral Biomedical Engineering, Ministry of Education (KLOBM) [J.J., Y.C., R.W., Y.-F.Z.], Department of Oral and Maxillofacial Surgery, School and Hospital of Stomatology [J.J., Y.C., Y.-F.Z.], Wuhan University, Wuhan 430079, China; Institute of Biophysics and Biochemistry, College of Life Science and Technology [K.F.], Huazhong University of Science and Technology, Wuhan 430074, China
\end{abstract}

\begin{abstract}
Our previous study demonstrated that allograft inflammatory factor-1 (AIF-1) is present in the vessels of infantile hemangiomas but neither in the vessels of vascular malformations, pyogenic granulomas, normal skin, placental tissues nor in the neovessels of squamous cell carcinomas of the tongue. The purpose of this study was to explore the impact of AIF-1 alterations on endothelial cells (EC). Stable introduction of AIF-1 to the human umbilical vein EC line (HUV-EC-C) in vitro revealed that AIF-1 enhances the proliferation and migration of the EC and promotes G0/G1-to-S-phase transition, accompanied by up-regulation of basic fibroblast growth factor $(p<0.05)$. In contrast, AIF-1 did not affect the expression of granulocyte colony-stimulating factor, VEGF-a, monocyte chemoattractant protein-1, or tissue inhibitor of metalloproteinase-1. AIF-1 expression was not induced by hypoxia, VEGF-a, basic fibroblast growth factor, or insulin-like growth factor-2 in EC. Taken together, these findings suggest that the impact of AIF-1 on EC would stimulate angiogenesis and consequently affect the progression of infantile hemangiomas. (Pediatr Res 67: 29-34, 2010)
\end{abstract}

$I^{\mathrm{n}}$ nfantile hemangioma (IH) is one of the most common benign tumors of infancy affecting $\sim 10 \%$ white babies (1). It has three different phases: the proliferating, involuting, and involuted phase. In the proliferating phase, endothelial cells (ECs) with increased activity and proliferation comprise a large portion of the tumor, suggesting the important role of ECs in the pathogenesis of IH. The ECs of IH immunoreact positively with normal endothelial markers of the blood vasculature, such as CD31, CD34, factor-VIII-related antigen, Ulex europaeus lectin I, FMS-like tyrosine kinase receptor-1, and VE-cadherin, except for CD146 (2). In addition to the normal endothelial markers, further immunohistochemical and gene expression studies have demonstrated that hemangioma ECs (hemECs) express glucose transporter type 1, Lewis Y antigen, Fc gamma receptor II, merosin (3), and indoleamine 2,3-deoxygenase (4) during all three phases, whereas some

Received April 16, 2009; accepted August 26, 2009.

Correspondence: Yi-Fang Zhao, M.D., Department of Oral and Maxillofacial Surgery, School and Hospital of Stomatology, Wuhan University, Wuhan 430079, China; e-mail: zhaoyfjj@yahoo.com.cn

Supported by Grant 20070486004 from the Ph.D. Programs Foundation of the Ministry of Education of China and by Grant NSFC 30872894 from National Natural Science Foundation of China (Y.-F.Z.).

J.J. and Y.C. contributed equally to the paper.
ECs in proliferating phases, coexpress CD133 and lymphatic vessel endothelial hyaluronan receptor-1 $(5,6)$, indicating that these cells are of placental origin or arrested in an early developmental vascular differentiation state. Recently, it has been verified that hemECs coexpress some markers typically associated with myeloid cells, including CD14, CD45, CD32, CD15, and CD83, demonstrating a close relationship between myeloid cells and hemECs (7). Moreover, our previous study showed that some hemECs coexpressed CD68 and allograft inflammatory factor-1 (AIF-1) (8).

The AIF-1 is a $17-\mathrm{kD}$, IFN- $\gamma$-inducible, $\mathrm{Ca}^{2+}$-binding, EF-hand protein that is encoded within the HLA class III genomic region and was first identified by Utans et al. (9) as a novel myeloid factor in rats, selectively expressed by inflammatory cells and inducible by IFN- $\gamma$. Human AIF-1 was originally cloned from activated macrophages in atherosclerotic allogenic heart grafts undergoing chronic immune rejection (GenBank accession number U49392) (10). The precise function of AIF-1 is still unknown. It is assumed that AIF-1 is a novel molecule involved in inflammatory responses, allograft rejection, and the activation and function of macrophages (11). It has been reported that AIF-1 is also expressed in macrophages and microglial cells in autoimmune diseases such as experimental autoimmune encephalomyelitis, neuritis, and uveitis models, suggesting that AIF-1 may play a pivotal role in autoimmunity (12). Furthermore, serial studies have demonstrated that AIF-1 stimulates both proliferation and migration of vascular smooth muscle cells (VSMCs) and macrophages $(13,14)$. Currently, AIF-1 expression was found in breast ductal tumor, and overexpression of AIF-1 facilitated tumor growth in female nude mice (15). ${ }^{1}$

The selective expression of AIF-1 in hemECs suggests that AIF-1 may play potential roles in the progression of IH. In this study, we tried to explore the impact of AIF-1 alterations on

\footnotetext{
Abbreviations: AIF-1, complementary allograft inflammatory factor-1; bFGF, basic fibroblast growth factor; EC, endothelial cell; G-CSF, granulocyte colony-stimulating factor; hemEC, hemangioma endothelial cell; IH, infantile hemangioma; MAPK, mitogen-activated protein kinase; MCP-1, monocyte chemoattractant protein-1; PAK 1, p21-activated kinases; TIMP-1, tissue inhibitor of metalloproteinase-1; VSMC, vascular smooth muscle cell
} 
ECs activity, molecular changes in these cells, and the possible role of AIF-1 in the development of IH.

\section{MATERIALS AND METHODS}

Cell culture and treatments. The review board of the Wuhan University Medical Ethics Committee approved this study. The human umbilical vein EC line HUV-EC-C (ATCC CRL 1730) was maintained in DMEM media (GIBCO Invitrogen, Carlsbad, CA) supplemented with $10 \%$ fetal bovine serum (FBS; Hyclone, Logan, UT) and $0.03 \mathrm{mg} / \mathrm{mL}$ EC growth supplement (ECGS) in a humidified $5 \% \mathrm{CO}_{2}$ atmosphere.

For VEGF-a, basic fibroblast growth factor (bFGF), and insulin-like growth factor (IGF)-2 (PeproTech Inc., Rocky Hill, NJ) treatments, HUVEC-C cells were seeded at a density per well of $5 \times 10^{5}$ in six-well plates. Confluent cells were serum starved (FBS was eliminated in all the following experiments) for $24 \mathrm{~h}$ and then treated with 100 or $200 \mathrm{ng} / \mathrm{mL}$ IGF-2, VEGF-a, or bFGF for 24 or $48 \mathrm{~h}$

For cell hypoxia treatment, the culture dishes were sealed in a modular incubator chamber, flushed with gas containing $1 \% \mathrm{O}_{2}, 5 \% \mathrm{CO}_{2}$, and $94 \% \mathrm{~N}_{2}$ for $5 \mathrm{~min}$, and incubated in this environment at $37^{\circ} \mathrm{C}$ for 24 or $48 \mathrm{~h}$.

Transfection and generation of $\mathrm{HUV}-\mathrm{EC}-\mathrm{C}$ cells stable expressing $\boldsymbol{A I F}-1$. The full-length cDNA of human AIF-1 was synthesized by Beijing Aoke Company (China) and inserted into the vector pcDNA3.1 (-). HUVEC-C cells (a density per well of $2 \times 10^{5}$ cells in 24-well plates) were stably transfected with $0.8 \mu \mathrm{g}$ of pcDNA3.1 (-)-AIF-1 plasmids using $2 \mu \mathrm{L}$ of Lipofectamine 2000 reagent (Invitrogen, Burlington, ON), according to the manufacturer's instructions. After $48 \mathrm{~h}$ of transfection, cells were trypsinized and replanted in DMEM with $10 \%$ FBS, $0.03 \mathrm{mg} / \mathrm{mL}$ ECGS, and $500 \mu \mathrm{g} / \mathrm{mL}$ G418 (Amresco Inc., Solon, OH). G418-resistant clones (AIF-1-HUV-EC-C) were selected and expanded, and the populations of resistant cells were pooled to avoid the effects of clonal variation. HUV-EC-C cells transfected with the vector plasmids pcDNA3.1 ( - ) (Vector-HUV-EC-C) were used as the control. In all the following experiments, the AIF-1-HUV-EC-C and VectorHUV-EC-C cells were maintained in DMEM supplemented with $10 \%$ FBS, $0.03 \mathrm{mg} / \mathrm{mL}$ ECGS, and $500 \mu \mathrm{g} / \mathrm{mL}$ G418.

Western blot. Cells were lysed on ice with Protein Extraction Reagent (Pierce, Rockford, IL). Lysates were incubated on ice for $60 \mathrm{~min}$ and clarified by centrifugation at $13,000 \times \mathrm{g}$ for $15 \mathrm{~min}$ at $4^{\circ} \mathrm{C}$. Equal amounts of total proteins from each sample were separated on the 15\% SDS-PAGE and transferred onto a polyvinylidene fluoride membrane (Millipore, Billerica, MA). Then, the membrane was immunoblotted with mouse anti-human AIF-1 [1:1000, a recently described MAb (8)] or goat anti-human beta-actin (1:1000; Santa Cruz Laboratories, Santa Cruz, CA), followed by incubation with secondary antibodies conjugated with horseradish peroxidase. Blots were visualized with enhanced chemiluminescence (Amersham Biosciences, Piscataway, $\mathrm{NJ}$ ), according to the manufacturer's instructions.

RNA isolation, cDNA synthesis, and semi-quantitative RT-PCR assay. The relative change in mRNA expression was assessed as previously described (16) with modifications. Total RNA from AIF-1-HUV-EC-C and Vector-HUV-EC-C cells was isolated with TRIZOL reagent (Invitrogen), according to the manufacturer's instructions. The RNA $(1.0 \mu \mathrm{g})$ was used as the template for the synthesis of cDNA $(20 \mu \mathrm{L})$ with OligodT and AMV reverse transcriptase (Takara, Japan). One fifth of the cDNA was PCR amplified using Taq polymerase (Takara) and specific primers. The primers, annealing temperatures, and cycle numbers are listed in Table 1 . One fifth of the PCR products were electrophoresed in $2 \%$ agarose gel and stained with ethidium bromide. The intensity of each band was analyzed densitometrically by using GeneTools software (Syngene, Frederick, MD). The relative levels of mRNA expression were quantified by comparison with the internal control (GAPDH). All the samples were run in triplicate, and the results were averaged.

MTT (thiazolyl blue tetrazolium bromide) assay. Cells were resuspended and seeded into 96-well plastic culture plates $\left(10^{3}\right.$ cells/well, six wells in each group). After seeding for 1,4 , and $7 \mathrm{~d}$, the quantity of viable cells was determined. One hundred microliters of sterile MTT $(5 \mathrm{mg} / \mathrm{mL}$; Sigma Chemical Co., St. Louis, MO) was added to each well and incubated for $4 \mathrm{~h}$ at $37^{\circ} \mathrm{C}$. Then, the MTT solution was carefully aspirated without disturbing the pellets, and the resulting blue formazan product was solubilized in $200 \mu \mathrm{L}$ dimethyl sulfoxide (Sigma Chemical Co.). The plates were swayed gently for complete dissolution of the crystals, and the OD values were determined at least in triplicate against a reagent blank at a test wavelength of $570 \mathrm{~nm}$ by spectrophotometry (Bio-tek, Winooski, VT). The values reflected the viable cell population in each well. The assays were performed in triplicate.

Flow cytometry. The cells $\left(10^{6}\right.$ cells) were harvested by trypsin treatment, collected by centrifugation, and fixed with ice-cold $70 \%$ ethanol overnight at $4^{\circ} \mathrm{C}$. Fixed cells were centrifuged and treated with $50 \mu \mathrm{g} / \mathrm{mL}$ RNase A
Table 1. Primers sequences and conditions used in semi-quantitative RT-PCR

\begin{tabular}{|c|c|c|c|}
\hline Gene & Sequences & $\begin{array}{c}\text { Annealing } \\
\text { temperature }\left({ }^{\circ} \mathrm{C}\right)\end{array}$ & $\begin{array}{l}\text { Cycle } \\
\text { number }\end{array}$ \\
\hline AIF-1 & & & \\
\hline $\begin{array}{l}\text { Forward } \\
\text { Reverse }\end{array}$ & $\begin{array}{l}\text { agacgatcccaaatatagcag } \\
\text { tagctctaggtgagtcttgg }\end{array}$ & 59 & 27 \\
\hline $\begin{array}{l}\text { G-CSF } \\
\quad \text { Forward } \\
\text { Reverse }\end{array}$ & $\begin{array}{l}\text { agacagggaagagcagaacgg } \\
\text { gccagagtgaggggtgcaa }\end{array}$ & 60 & 30 \\
\hline $\begin{array}{l}\text { VEGF-a } \\
\text { Forward } \\
\text { Reverse }\end{array}$ & $\begin{array}{l}\text { tcatctctcctatgtgctggc } \\
\text { atgaactttctgctctctgg }\end{array}$ & 57 & 34 \\
\hline $\begin{array}{l}\text { b-FGF } \\
\text { Forward } \\
\text { Reverse }\end{array}$ & $\begin{array}{l}\text { gtgtgtgctaaccgttacct } \\
\text { gctcttagcagacattggaag }\end{array}$ & 55 & 30 \\
\hline $\begin{array}{l}\text { TIMP-1 } \\
\text { Forward } \\
\text { Reverse }\end{array}$ & $\begin{array}{l}\text { ccttctgcaattccgacctcgtc } \\
\text { cgggcaggattcaggctatctgg }\end{array}$ & 60 & 30 \\
\hline $\begin{array}{l}\text { MCP-1 } \\
\text { Forward } \\
\text { Reverse }\end{array}$ & $\begin{array}{l}\text { gctgaccccaagcagaagtg } \\
\text { tcttcggagtttgggtttgc }\end{array}$ & 56 & 35 \\
\hline $\begin{array}{l}\text { GAPDH } \\
\text { Forward } \\
\text { Reverse }\end{array}$ & $\begin{array}{l}\text { aacggatttggtcgtattggg } \\
\text { caggggtgctaagcagttgg }\end{array}$ & 56 & 30 \\
\hline
\end{tabular}

(Amresco) for $15 \mathrm{~min}$ at $37^{\circ} \mathrm{C}$, and then, the cells were incubated with 5 $\mu \mathrm{g} / \mathrm{mL}$ propidium iodide (Sigma Chemical Co.) for $30 \mathrm{~min}$ at room temperature in the dark. The cell cycle distribution was detected by flow cytometry (Becton Dickinson, Franklin Lakes, NJ).

Wound healing assay and migration assay. EC motility assay was performed as described previously (17). Cells were seeded into six-well plastic culture plates and grown until confluence, at which time monolayers were scraped with a pipette tip to create a linear wound in the center of the chamber. The wound tracks were immediately washed with PBS to remove any detached cells, and fresh media were added. At $72 \mathrm{~h}$ after wounding, cells were fixed and stained with acridine orange (Sigma Chemical Co.). Six random images were obtained using a fluorescent microscope with a camera (Leica, Wetzlar, Germany). Cell motility in terms of wound closure was measured by counting the number of cells that move into the wound in each field. Migration assays for ECs were performed in a modified Boyden chamber using a standard 48-well chemotaxis chamber (Neuro Probe Inc., Gaithersburg, MD), according to the method described by Yamaguchi et al. (18). Eight-micron, nucleopore, polyvinylpyrrolidine-free, polycarbonate filters (Corning, Cambridge, MA) were coated with $100 \mu \mathrm{g} / \mathrm{mL}$ of collagen type 1 (Amresco) in $0.2 \mathrm{~N}$ acetic acid for $2 \mathrm{~d}$ and air dried. The filter was placed over a bottom chamber containing $5 \mathrm{ng} / \mathrm{mL} \mathrm{VEGF}_{165}$ (PeproTech) in DMEM with $0.025 \%$ BSA. Cells were serum starved for $24 \mathrm{~h}$ and suspended in DMEM, and 10,000 cells in $50 \mu \mathrm{L}$ were added to each well in the upper chamber. The assembled chemotaxis chamber was incubated for $6 \mathrm{~h}$ at $37^{\circ} \mathrm{C}$ with $5 \% \mathrm{CO}_{2}$ to allow cells to migrate through the collagen-coated polycarbonate filter. Nonmigrated cells on the upper surface of the filter were removed, and the filter was stained with hematoxylin. The total number of migrated cells was counted, and the assays were performed in quadruplicate.

Real-time PCR assay. Real-time PCR was performed using RotorGene3000 Advanced (Dual Channel) Real-Time DNA Detection System (Corbett Life Science, Australia). The amplification protocol consisted of incubations at $95^{\circ} \mathrm{C}$ for $10 \mathrm{~s}, 62^{\circ} \mathrm{C}$ for $10 \mathrm{~s}$, and $72^{\circ} \mathrm{C}$ for $30 \mathrm{~s}$ for 40 cycles. The primers and probes for VEGF-a, bFGF, and beta-actin are shown in Table 2. All PCR reactions were performed in triplicate. The relative expression levels were analyzed using the "Relative standard curve methods" (19).

ELISA assay. Cells were plated in six-well plates until confluence, and then $1 \mathrm{~mL}$ of the serum-free medium was added. After $24 \mathrm{~h}$, the media were collected, and the secretion of VEGF and bFGF was evaluated using commercially available sandwich ELISA kits (R\&D Systems, Minneapolis, MN), according to the manufacturer's instructions. Results were normalized by the number of producing cells and reported as picogram of growth factors $/ 10^{6}$ cells $/ 24 \mathrm{~h}$.

Statistical analysis. For all the experiments, results were analyzed using $t$ test. $p<0.05$ was considered statistically significant. 
Table 2. Primers and probes sequences used in real-time PCR

\begin{tabular}{cl}
\hline Gene & \multicolumn{1}{c}{ Sequences } \\
\hline VEGF-a & \\
Forward & CGAGGGCCTGGAGTGTGT \\
Reverse & GCATTCACATTTGTGTGCTGTAG \\
Probe & F-CATGCAGATTATGCGGATCAAACCTCAC-P \\
bFGF & \\
Forward & CCGACGGCCGAGTTGAC \\
Reverse & AAGCCAGTAATCTTCCATCTTCCTT \\
Probe & F-AGAAGAGCGACCCTCACATCAAGCTACAA-P \\
Beta-actin & \\
Forward & CCTGGCACCCAGCACAAT \\
Reverse & GCTGATCCACATCTGCTGGAA \\
Probe & F-ATCAAGATCATTGCTCCTCCTGAGCGC-P \\
\hline
\end{tabular}

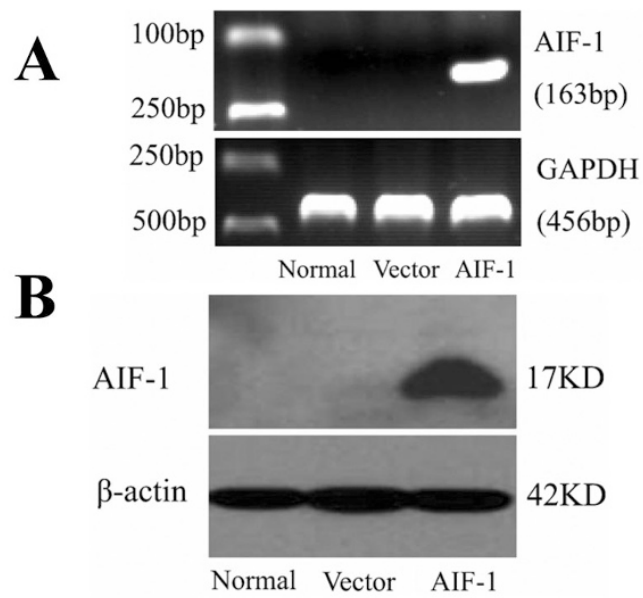

Figure 1. Expression of AIF-1 in the transfected endothelial cells. After transfection with pcDNA3.1 (-)-AIF-1 or empty vector, the expression of the mRNA and protein of AIF-1 was analyzed by RT-PCR $(A)$ and Western blot $(B)$.

\section{RESULTS}

Detection of AIF-1 expression in HUV-EC-C cells. The mRNA and protein of AIF-1 were detected in AIF-1-HUVEC-C cells (Fig. 1), whereas AIF-1 was negative in either the normal HUV-EC-C or the Vector-HUV-EC-C cells. This result is consistent with the studies by Autieri and us, demonstrating that AIF-1 was not expressed in the normal blood vessel $(8,20)$.

AIF-1 enhanced the proliferation and migration of HUVEC-C cells. In previous reports $(13,14)$, it was demonstrated that AIF-1 enhanced proliferation and migration of the macrophages and VSMCs. The results that only the ECs of IH expressed AIF-1 evoked our interest in understanding the role of AIF-1 in ECs; therefore, we performed MTT assay on HUV-EC-C either stably transfected with pcDNA3.1 (-)AIF-1 or with empty vector. Significantly increased cell proliferation rate was observed in HUV-EC-C cells transfected with AIF-1 (an average of $\sim 53 \%$ ) compared with the EC lacking the protein (Fig. $2 A, p<0.01, n=6$ ). The result from flow cytometry showed that AIF-1-HUV-EC-C cells exhibited a decreased proportion in the static phase (G0/G1) and an increased proportion in the synthetic ( $\mathrm{S}$ ) and mitotic phases (G2/M; Fig. 2B). Therefore, expression of AIF-1 in HUV-
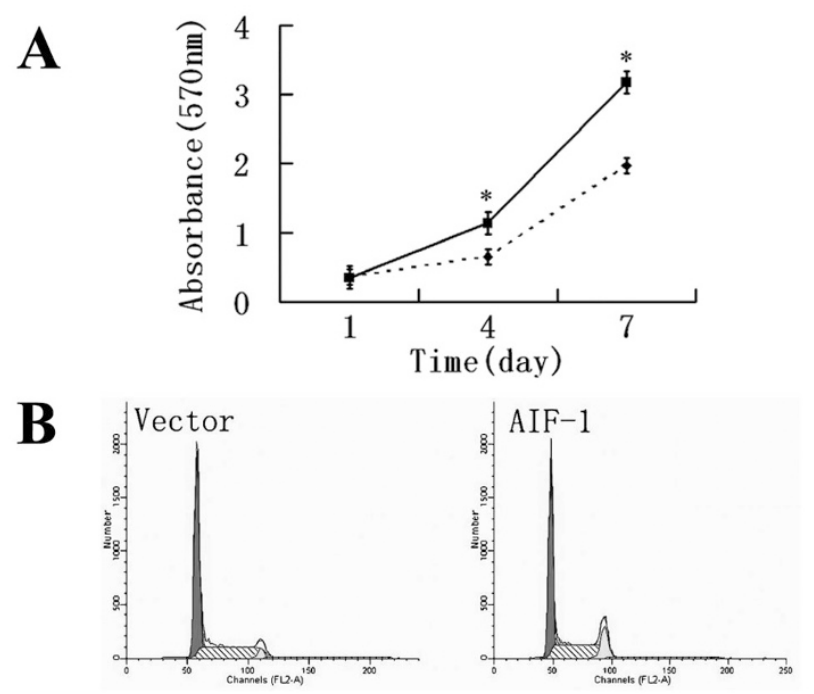

Figure 2. AIF-1 overexpression promoted the proliferation of the endothelial cell. (A) The MTT assay indicated that the percentage of viable cells in AIF-1-HUV-EC-C group (solid line) was significantly higher than those in Vector-HUV-EC-C group (dotted line) during the culture period $\left({ }^{*} p<0.05\right.$, $n=6)$. (B) The result of flow cytometry showed that AIF-1-expressing cells exhibited a decreased proportion of cells in the static phase (G0/G1) and an increased proportion in the synthesis (S) and mitotic phase (G2/M) (VectorHUV-EC-C group: G0/G1, 65.39\%; S, 31.19\%; G2/M, 3.43\% and AIF-1HUV-EC-C group: G0/G1, 53.22\%; S, 38.78\%; G2/M, 8\%).

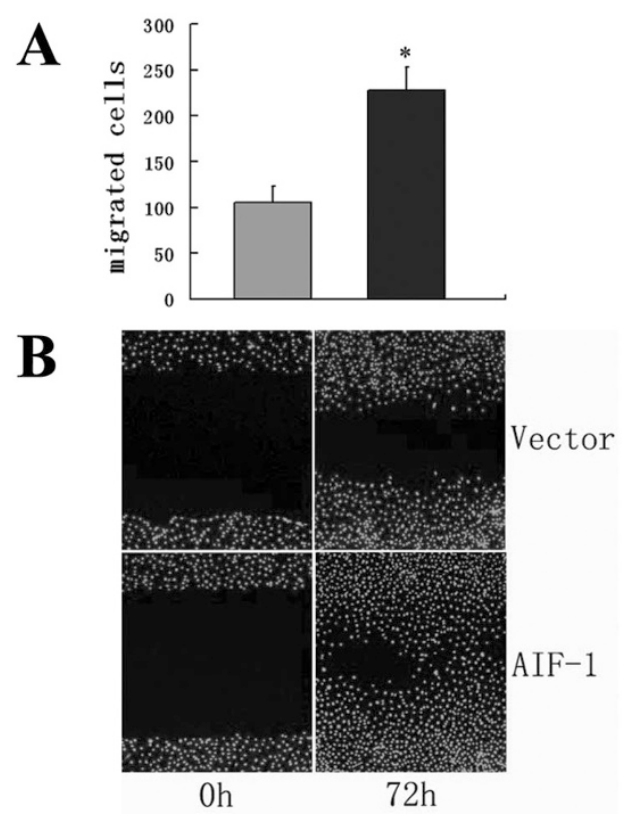

Figure 3. AIF-1 overexpression promoted the migration of the endothelial cell. The migration assay $(A)$ and the wound healing motility assay $(B)$ showed that in contrast to HUV-EC-C transfected with empty vector alone (Vector-HUV-EC-C group: gray column), cell migration was dramatically enhanced in AIF-1-HUV-EC-C cells (black column, ${ }^{*} p<0.01, n=4$ ).

EC-C cells promoted cell cycle progression from $\mathrm{G} 0 / \mathrm{G} 1$ phase to $\mathrm{S}$ and $\mathrm{G} 2 / \mathrm{M}$ phase.

We further investigated the effects of AIF-1 overexpression on the ECs chemotaxis. Cells were seeded into Boyden chambers, and differences in chemotaxis were quantitated by counting migrated cells. Figure $3 A$ showed that cells stably transduced with AIF-1 migrated 2.15-fold faster $(p<0.01, n=4)$ 

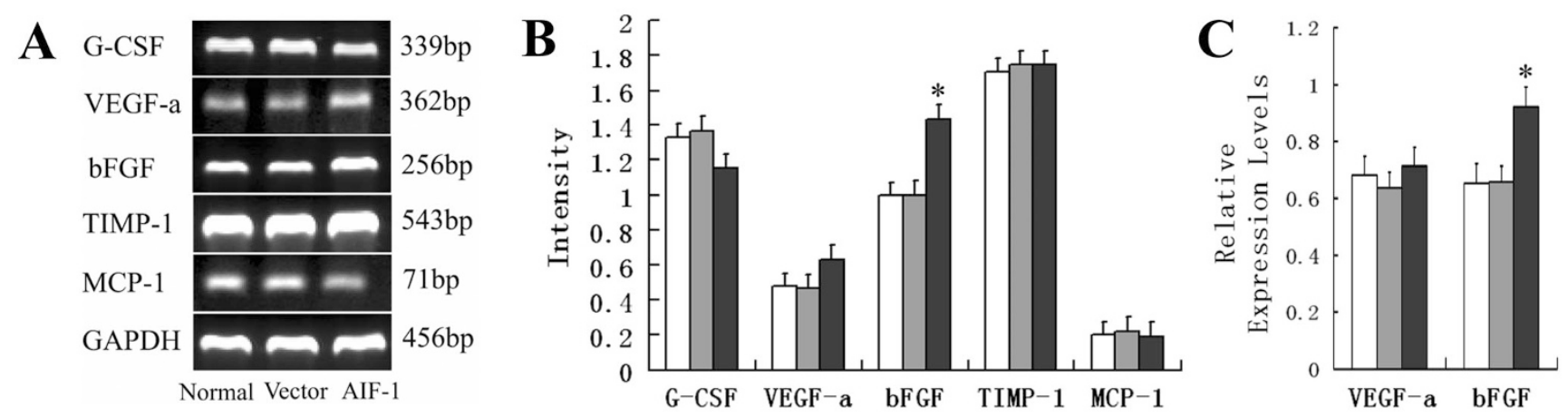

Figure 4. The mRNA level of G-CSF, VEGF-a, bFGF, TIMP-1, and MCP-1 in HUV-EC-C cells and HUV-EC-C transfected with AIF-1 or vector detected by semi-quantitative RT-PCR and real-time PCR. ( $A$ and $B$ ) The result of semi-quantitative RT-PCR showed a significant increase in bFGF expression in the transfected cells $(* p<0.05, n=3$ ), whereas no difference in G-CSF, VEGF-a, MCP-1, and TIMP-1. (C) Real-time PCR assays showed a significant increase in bFGF expression in the AIF-1 transfected HUV-EC-C $\left({ }^{*} p<0.05, n=3\right.$ ), whereas no difference in VEGF-a (normal HUV-EC-C group: white column; Vector-HUV-EC-C group: gray column; AIF-1-HUV-EC-C group: black column).

than control cells, indicating a positive effect of AIF-1 on cell migration. To additionally demonstrate a function for AIF-1 expression in the ECs migration, the directional migration ability of the cells was examined by a wound healing assay. The data presented in Figure $3 B$ showed that in contrast to controls, cell migration was dramatically enhanced in AIF-1HUV-EC-C cells.

AIF-1 up-regulated bFGF expression in HUV-EC-C cells. To further understand the mechanism by which AIF-1 modulates the proliferation and migration of ECs, the expression levels of granulocyte colony-stimulating factor (G-CSF), VEGF-a, bFGF, monocyte chemoattractant protein-1 (MCP1), and tissue inhibitor of metalloproteinase-1 (TIMP-1), which are involved in the pathogenesis of $\mathrm{IH}$, were evaluated by semi-quantitative RT-PCR assay. As shown in Figure $4 A$ and $B$, there was a significant increase in bFGF expression in AIF-1-HUV-EC-C cells compared with the cells transfected with vector only ( $p<0.05, n=3$ ), whereas no difference was observed in the expression of G-CSF, VEGF-a, MCP-1, and TIMP-1.

Because both bFGF and VEGF-a are the most important angiogenic factors, which play critical roles in the pathogenesis of $\mathrm{IH}$, we then further analyzed their expressions by real-time PCR. The results revealed the up-regulation of bFGF in AIF-1-HUV-EC-C cells (Fig. $4 C, p<0.05, n=3$ ) but no difference in VEGF-a compared with control cells. In addition, ELISA assay also showed that the levels of bFGF in the media were higher in AIF-1-HUV-EC-C cells than those in the control cells $\left(261 \pm 51\right.$ versus $153 \pm 36 \mathrm{pg} / 10^{6}$ cells $/ 24 \mathrm{~h}$, $p<0.05, n=3)$ but no difference in VEGF-a $(126 \pm 38$ versus $143 \pm 27 \mathrm{pg} / 10^{6}$ cells $/ 24 \mathrm{~h}$ ).

Hypoxia, VEGF-a, bFGF, and IGF-2 could not induce the expression of AIF-1 in $\mathrm{HUV}-\mathrm{EC}-\mathrm{C}$ cells. Considering that AIF-1 is a cytokine-responsive transcript (21), we tried to determine whether the factors that are potential causes for $\mathrm{IH}$, including hypoxia, VEGF-a, bFGF, and IGF-2 (22-24), could induce the expression of AIF-1 in ECs. To test this, we treated HUV-EC-C cells with hypoxia, VEGF-a, bFGF, and IGF-2. However, the results showed that these factors, independent on the concentration and the time, could not induce the expression of AIF-1 in HUV-EC-C cells (data not shown).

\section{DISCUSSION}

According to the classification by the International Society for the Study of Vascular Anomalies, IH is clarified as vascular tumor (1). We had reported AIF-1 expression only in the vessels of IH but neither in the vessels of vascular malformations, normal skin, pyogenic granulomas, or placental tissues nor in the neovessels of squamous cell carcinoma of the tongue. However, the role of AIF-1 in IH has not been elaborated. In this study, we observed that AIF-1 can enhance the proliferation and migration of EC, probably through augmenting the expression of bFGF.

AIF-1 is a polypeptide of $17 \mathrm{kD}$ that contains a 12-amino acid region, similar to $\mathrm{Ca}^{2+}$-binding EF-hand domains (9). Involvement of EF-hand family proteins suggests that the common amino acid motif is capable of binding intracellular free $\mathrm{Ca}^{2+}$, an intracellular second messenger. A wide variety of cellular processes, such as nucleotide metabolism, cell cycle control, differentiation, and signal transduction are regulated by oscillating shifts in compartment-bound $\mathrm{Ca}^{2+}(25)$. Studies on in vitro systems have demonstrated that AIF-1 transfection stimulated the proliferation of transformed VSMCs, T lymphocytes, and macrophages $(14,26,27)$. Our results showed that overexpression of AIF-1 in HUV-EC-C led to a higher cell proliferation rate compared with empty vector controls. Furthermore, the cell cycle examination by flow cytometry indicated that AIF-1-expressing cells moved more rapidly through the cell cycle than the control cells did, in as much as they peaked in S phase earlier. Nevertheless, our previous study showed that proliferating neovessels in squamous cell carcinoma and pyogenic granulomas expressed no AIF-1, suggesting that expression of AIF-1 is, but not indispensable, able to promote the proliferation of ECs.

Cell migration requires actin polymerization at the leading edge of the cell, and continuous remodeling of actin at the cell periphery is necessary to drive cell locomotion. AIF-1 inter- 
action with and polymerization of nonmuscle actin (26) prompted us to determine whether AIF-1 overexpression promoted ECs migration. Similar to what has been previously reported in human VSMCs and MOLT-4 cell $(26,27)$, overexpression of AIF-1 increased ECs migration in vitro compared with empty vector controls.

Considering that both entry into the cell cycle and promotion of cell migration are driven by growth factors and that several growth factors are involved in the pathogenesis of $\mathrm{IH}$, we tried to determine whether the enhancement of proliferation and migration in ECs transfected with AIF-1 was a consequence of growth factor expression. Other investigators have found that overexpression of AIF-1 leads to induction of cytokine expression. Watano et al. (28) have found that transfection of AIF-1 into a mouse macrophage cell line results in production of interleukin (IL)-6, IL-10, and IL-12 in response to lipopolysaccharide stimulation. Furthermore, a transgenic mouse with restricted expression of AIF-1 in lymphoid tissue (29) showed an exacerbation of experimental inflammatory colitis accompanied with an augmentation of inflammatory cytokines. Recent studies have demonstrated that AIF-1 can stimulate the release of cytokines, including bFGF, PDGF, TGF- $\beta$, G-CSF, and MCP-1. However, the role of AIF-1 was quite variable among the different types of cells and even the same kind of cells with different maturation stages $(13,14,21)$. Angiogenesis has been considered as an etiology of IH (23); therefore, the angiogenic and antiangiogenic factors involved in the development of $\mathrm{IH}$, including G-CSF, VEGF, bFGF, TIMP-1, and MCP-1, were tested in this study. Our result showed that AIF-1 did not affect the expression of G-CSF, VEGF, TIMP-1, MCP-1 but up-regulate the expression of bFGF. The positive effect of AIF-1 on bFGF was further supported by the parallel expression pattern of AIF-1 and bFGF, both of which are highly expressed in the proliferating and involuting phases of $\mathrm{IH}(8,23)$. Taken together, these findings strongly suggest that AIF-1 may augment the expression of bFGF in IH.

Recent research showed that both mitogen-activated protein kinase (MAPK) p44/42 and PAK1 signal pathways are activated in the ECs that overexpress AIF-1 without activation of p38 MAPK signal pathway (30). The expression of bFGF has been shown to depend on activating MAPK p44/42 signaling pathway $(31,32)$, and these results suggest that AIF-1 may promote the expression of bFGF through activating MAPK p44/42 signaling pathway. However, the kinase MAPK p44/42 has also been shown to regulate upstream signaling events that control the transcriptions of cytokines, including bFGF, G-CSF, TIMP-1, MCP-1, and VEGF (31-35). Our results indicated that AIF-1 in ECs could only up-regulate the expression of bFGF, rather than G-CSF, VEGF, TIMP-1, and MCP-1. Together, these data provide impetus to explore the signal transduction pathways leading to up-regulation of bFGF in HUV-EC-C.

Because AIF-1 is a cytokine-responsive transcript, we tested whether the expression of AIF-1 in IH could be induced by the factors, including VEGF, bFGF, and IGF-2, that are potentially important mediators in IH. However, our results showed that none of the factors could stimulate the expression of AIF-1. Given that AIF-1 is an early-response gene in diseases (36), the upstream regulator of VEGF, bFGF, and IGF-2 was further examined. Several pieces of evidences, at the molecular, cellular, and clinical levels, suggest a possible role for hypoxia in IH pathogenesis. Hypoxia is sensed by cells, which then responded by modifying gene expression. These modifications can enhance the survival of cells in low oxygen conditions as well as induce the expression of factors that promote the growth of new blood vessels. We sought to determine whether hypoxia, the upstream regulator of VEGF, bFGF, and IGF-2 in IH $(24,37)$, could induce the expression of AIF-1 in ECs. The results showed that the expression of AIF-1 was not detectable in ECs even after they had been incubated under low oxygen condition for $48 \mathrm{~h}$. Although bFGF induces AIF-1 expression in VSMCs (21), we and Tian et al. (30) showed that bFGF was not capable of inducing AIF-1 expression in ECs. The reason why bFGF could not induce AIF-1 expression in ECs needs to be further investigated.

In conclusion, AIF-1 can enhance the proliferation and migration of EC, probably through augmenting the expression of bFGF. The impact of AIF-1 on ECs would stimulate angiogenesis and consequently exacerbate IH. Further investigation is needed to determine which factor induces the expression of AIF-1 in IH.

\section{REFERENCES}

1. Mulliken JB, Fishman SJ, Burrows PE 2000 Vascular anomalies. Curr Probl Surg 37:517-584

2. Li Q, Yu Y, Bischoff J, Mulliken JB, Olsen BR 2003 Differential expression of CD146 in tissues and EC derived from infantile haemangioma and normal human skin. J Pathol 201:296-302

3. North PE, Waner M, Mizeracki A, Mrak RE, Nicholas R, Kincannon J, Suen JY, Mihm MC Jr 2001 A unique microvascular phenotype shared by juvenile hemangiomas and human placenta. Arch Dermatol 137:559-570

4. Ritter MR, Moreno SK, Dorrell MI, Rubens J, Ney J, Friedlander DF, Bergman J, Cunningham BB, Eichenfield L, Reinisch J, Cohen S, Veccione T, Holmes R, Friedlander SF, Friedlander M 2003 Identifying potential regulators of infantile hemangioma progression through large-scale expression analysis: a possible role for the immune system and indoleamine 2,3 dioxygenase (IDO) during involution. Lymphat Res Biol 1:291-299

5. Yu Y, Flint AF, Mulliken JB, Wu JK, Bischoff J 2004 Endothelial progenitor cells in infantile hemangioma. Blood 103:1373-1375

6. Dadras SS, North PE, Bertoncini J, Mihm MC, Detmar M 2004 Infantile hemangiomas are arrested in an early developmental vascular differentiation state. Mod Pathol 17:1068-1079

7. Ritter MR, Reinisch J, Friedlander SF, Friedlander M 2006 Myeloid cells in infantile hemangioma. Am J Pathol 168:621-628

8. Jia J, Bai Y, Fu K, Sun ZJ, Chen XM, Zhao YF 2008 Expression of allograft inflammatory factor-1 and CD68 in haemangioma: implication in the progression of haemangioma. Br J Dermatol 159:811-819

9. Utans U, Arceci RJ, Yamashita Y, Russell ME 1995 Cloning and characterization of allograft inflammatory factor-1: a novel macrophage factor identified in rat cardiac allografts with chronic rejection. J Clin Invest 95:2954-2962

10. Utans U, Quist WC, McManus BM, Wilson JE, Arceci RJ, Wallace AF, Russell ME 1996 Allograft inflammatory factory-1. A cytokine-responsive macrophage molecule expressed in transplanted human hearts. Transplantation 61:1387-1392

11. Deininger MH, Meyermann R, Schluesener HJ 2002 The allograft inflammatory factor-1 family of proteins. FEBS Lett 514:115-121

12. Schluesener HJ, Seid K, Kretzschmar J, Meyermann R 1998 Allograft-inflammatory factor-1 in rat experimental autoimmune encephalomyelitis, neuritis, and uveitis: expression by activated macrophages and microglial cells. Glia 24:244-251

13. Chen X, Kelemen SE, Autieri MV 2004 AIF-1 expression modulates proliferation of human vascular smooth muscle cells by autocrine expression of G-CSF. Arterioscler Thromb Vasc Biol 24:1217-1222

14. Yang ZF, Ho DW, Lau CK, Lam CT, Lum CT, Poon RT, Fan ST 2005 Allograft inflammatory factor-1 (AIF-1) is crucial for the survival and pro-inflammatory activity of macrophages. Int Immunol 17:1391-1397

15. Liu S, Tan WY, Chen QR, Chen XP, Fu K, Zhao YY, Chen ZW 2008 Daintain/ AIF-1 promotes breast cancer proliferation via activation of the NF-kappaB/cyclin D1 pathway and facilitates tumor growth. Cancer Sci 99:952-957

16. Kitawaki J, Koshiba H, Ishihara H, Kusuki I, Tsukamoto K, Honjo H 2000 Expression of leptin receptor in human endometrium and fluctuation during the menstrual cycle. J Clin Endocrinol Metab 85:1946-1950 
17. Guo HB, Lee I, Kamar M, Akiyama SK, Pierce M 2002 Aberrant $N$-glycosylation of beta-1 integrin causes reduced alpha-5-beta-1 integrin clustering and stimulates cell migration. Cancer Res 62:6837-6845

18. Yamaguchi N, Anand-Apte B, Lee M, Sasaki T, Fukai N, Shapiro R, Que I, Lowik C, Timpl R, Olsen BR 1999 Endostatin inhibits VEGF-induced endothelial cell migration and tumor growth independently of zinc binding. EMBO J 18:4414-4423

19. Cikos S, Bukovska A, Koppel J 2007 Relative quantification of mRNA: comparison of methods currently used for real-time PCR data analysis. BMC Mol Biol 8:113

20. Autieri MV, Kelemen SE, Wendt KW 2003 AIF-1 is an actin-polymerizing and Rac1-activating protein that promotes vascular smooth muscle cell migration. Circ Res 92:1107-1114

21. Autieri MV, Carbone C, Mu A 2000 Expression of allograft inflammatory factor-1 is a marker of activated human vascular smooth muscle cells and arterial injury. Arterioscler Thromb Vasc Biol 20:1737-1744

22. Kleinman ME, Greives MR, Churgin SS, Blechman KM, Chang EI, Ceradini DJ, Tepper OM, Gurtner GC 2007 Hypoxia-induced mediators of stem/progenitor cell trafficking are increased in children with hemangioma. Arterioscler Thromb Vasc Biol 27:2664-2670

23. Takahashi K, Mulliken JB, Kozakewich HP, Rogers RA, Folkman J, Ezekowitz RA 1994 Cellular markers that distinguish the phases of hemangioma during infancy and childhood. J Clin Invest 93:2357-2364

24. Picard A, Boscolo E, Khan ZA, Bartch TC, Mulliken JB, Vazquez MP, Bischoff J 2008 IGF-2 and FLT-1/VEGF-R1 mRNA levels reveal distinctions and similarities between congenital and common infantile hemangioma. Pediatr Res 63:263-267

25. Li W, Llopis J, Whitney M, Zlokarnik G, Tsien RY 1998 Cell-permeant caged InsP3 ester shows that $\mathrm{Ca} 2+$ spike frequency can optimize gene expression. Nature 392:936-941

26. Kelemen SE, Autieri MV 2005 Expression of allograft inflammatory factor-1 in T lymphocytes: a role in T-lymphocyte activation and proliferative arteriopathies. Am J Pathol 167:619-626

27. Autieri MV, Carbone CM 2001 Overexpression of allograft inflammatory factor- 1 promotes proliferation of vascular smooth muscle cells by cell cycle deregulation. Arterioscler Thromb Vasc Biol 21:1421-1426
28. Watano K, Iwabuchi K, Fujii S, Ishimori N, Mitsuhashi S, Ato M, Kitabatake A, Onoe K 2001 Allograft inflammatory factor-1 augments production of interleukin-6, -10 and -12 by a mouse macrophage line. Immunology 104:307-316

29. Morohashi T, Iwabuchi K, Watano K, Dashtsoodol N, Mishima T, Nakai Y, Shimada S, Nishida R, Fujii S, Onoe K 2003 Allograft inflammatory factor-1 regulates trinitrobenzene sulphonic acid-induced colitis. Immunology 110:112-119

30. Tian Y, Jain S, Kelemen SE, Autieri MV 2009 AIF-1 expression regulates endothelial cell activation, signal transduction, and vasculogenesis. Am J Physiol Cell Physiol 296:C256-C266

31. Chaturvedi K, Sarkar DK 2005 Role of protein kinase C-Ras-MAPK p44/42 in ethanol and transforming growth factor-beta3-induced basic fibroblast growth factor release from folliculostellate cells. J Pharmacol Exp Ther 314:1346-1352

32. Chaturvedi K, Sarkar DK 2004 Involvement of protein kinase C-dependent mitogenactivated protein kinase p44/42 signaling pathway for cross-talk between estradio and transforming growth factor-beta 3 in increasing basic fibroblast growth factor in folliculostellate cells. Endocrinology 145:706-715

33. Wang YQ, Luk JM, Chu AC, Ikeda K, Man K, Kaneda K, Fan ST 2006 TNP-470 blockage of VEGF synthesis is dependent on MAPK/COX-2 signaling pathway in PDGF-BB-activated hepatic stellate cells. Biochem Biophys Res Commun 341:239244

34. Ramer R, Hinz B 2008 Inhibition of cancer cell invasion by cannabinoids via increased expression of tissue inhibitor of matrix metalloproteinases-1. J Natl Cancer Inst 100:59-69

35. Jawan B, Kao YH, Goto S, Pan MC, Lin YC, Hsu LW, Nakano T, Lai CY, Sun CK, Cheng YF, Tai MH, Eng HL, Wang CS, Huang CJ, Lin CR, Chen CL 2008 Propofol pretreatment attenuates LPS-induced granulocyte-macrophage colony-stimulating factor production in cultured hepatocytes by suppressing MAPK/ERK activity and NF-kappaB translocation. Toxicol Appl Pharmacol 229:362-373

36. Liu G, Ma H, Jiang L, Zhao Y 2007 Allograft inflammatory factor-1 and its immune regulation. Autoimmunity 40:95-102

37. Feldser D, Agani F, Iyer NV, Pak B, Ferreira G, Semenza GL 1999 Reciprocal positive regulation of hypoxia-inducible factor 1alpha and insulin-like growth factor 2. Cancer Res 59:3915-3918 